\title{
Các nhân tố ảnh hưởng đến sự minh bạch trách nhiệm xã hội của các công ty niêm yết Việt Nam
}

\section{Determinants of corporate social responsibility disclosure of Vietnamese listed companies}

\author{
Lưu Thị Thái Tâm ${ }^{1 *}$, Ngô Mỹ Trân ${ }^{2}$ \\ ${ }^{1}$ Khoa Kinh tế-QTKD, Trường Đại học An Giang, Đại học Quốc gia TP. HCM, Việt Nam \\ ${ }^{2}$ Khoa Kinh tế, Đại học Cần Thơ, Việt Nam \\ *Tác giả liên hệ, Email: ltttam@agu.edu.vn
}

THÔNG TIN

DOI: 10.46223/HCMCOUJS. econ.vi.15.3.1336.2020

Ngày nhận: 10/04/2020

Ngày nhận lại: 01/06/2020

Duyệt đăng: 02/06/2020

Tù khóa:

minh bạch trách nhiệm xã hội, sự kiêm chức của $\mathrm{CEO}$, hội đồng quản trị, sở hữu nhà nước, sở hữu nước ngoài

Keywords:

social responsibility transparency, CEO duality, board, state ownership, foreign ownership
TÓM TẮT

Nghiên cứu nhằm phân tích các nhân tố ảnh hưởng đến sự minh bạch trách nhiệm xã hội (CSR) của các công ty niêm yết trên thị trường chứng khoán Việt Nam. Số liệu được thu thập từ 323 công ty niêm yết phi tài chính đang niêm yết trên sàn giao dịch chứng khoán Hồ Chí Minh và Hà Nội giai đoạn 2013-2017. Kết quả nghiên cứu cho thấy các nhân tố gồm quy mô công ty, số năm hoạt động, tỷ lệ sở hữu nước ngoài có ảnh hưởng rất tích cực đến mức độ minh bạch CSR của các công ty. Tuy nhiên, các nhân tố gồm sự kiêm chức của $\mathrm{CEO}$, tỷ lệ sở hữu nhà nước, tỷ lệ vay nợ và quy mô hội đồng quản trị có ảnh hưởng ngược chiều đến mức độ minh bạch CSR của các công ty. Ngoài ra, kết quả phân tích còn cho thấy mỗi nhân tố có sự ảnh hưởng khác nhau đến từng khía cạnh trách nhiệm thành phần. Dựa trên kết quả phân tích, một số hàm ý chính sách được đề xuất nhằm cải thiện sự minh bạch CSR cho các công ty niêm yết Việt Nam trong tương lai.

ABSTRACT
The study was carried out the factors to analyze the
determinants of the transparency of corporate social
responsibility (CSR) of listed companies on Vietnamese Stock
Market. The data was collected from 323 non-financial listed
companies on Ho Chi Minh and Hanoi Stock Exchange from
2013 to 2017. The findings indicated the factors including
company size, comapy age, percentage of foreign ownership had
positive influence on CSR transparency. However, the factors
including CEO duality, state ownership rate, debt ratio and board
size had negative influence on CSR transparency. In addition, the
results indicated the different influence of each factor to each
component aspect. Based on findings, some policy implications
were proposed to improve the CSR transparency in the future.




\section{Giới thiệu}

Xu hướng toàn cầu hóa diễn ra mạnh mẽ đã và đang mang lại nhiều cơ hội cũng như thách thức cho các doanh nghiệp Việt Nam, cụ thể đã làm tăng áp lực cạnh tranh cho các doanh nghiệp do sự xóa bỏ các rào cản thương mại, các quốc gia nhập khẩu tiến hành bảo hộ sản xuất trong nước bằng nhiều biện pháp phi thuế quan như yêu cầu các tiêu chuẩn kỹ thuật, môi trường và lao động, sử dụng nhiều biện pháp phòng vệ thương mại, chống bán phá giá và chống trợ cấp. Để thích ứng, các công ty nhất là các công ty có hoạt động kinh doanh quốc tế phải tăng cường thực hiện và minh bạch trách nhiệm xã hội (Corporate social responsibility-CSR). Nhiều nghiên cứu trước đây đã chỉ ra những lợi ích đạt được khi công ty thực hiện và minh bạch CSR. Haniffa và Cooke (2005) lập luận rằng thực hiện minh bạch trách nhiệm xã hội và môi trường sẽ làm tăng danh tiếng cho công ty, tạo được niềm tin với các bên liên quan và gia tăng hiệu quả tài chính (Allouche \& Laroche, 2006), tăng mức độ mua sắm của khách hàng (Brown \& Dacin, 1997), dễ dàng tiếp cận với nguồn vốn vay ưu đãi và gia tăng giá trị cho cổ đông (Roberts, 1992), thu hút được nhiều nhà đầu tư (Laufer, 2003). Ngoài ra, thông tin minh bạch CSR của các công ty sẽ cung cấp thông tin cho chính phủ trong nhằm ban hành các chính sách quản lý tốt hơn (Moon \& Vogel, 2009).

Sau gần 20 năm hình thành và phát triển, thị trường chứng khoán (TTCK) Việt Nam đang trên đà tăng trưởng tốt, quy mô vốn hóa thị trường tăng nhanh cùng với sự xuất hiện ngày càng nhiều các công ty cổ phần niêm yết mới. Thực trạng này tất yếu dẫn đến sự đòi hỏi các công ty phải tăng cường thực hiện tốt hơn sự minh bạch thông tin bao gồm thông tin CSR nhằm tuân thủ theo các quy định công bố thông tin của Thông tư số 155/2015/TT-BTC đối với các công ty khi niêm yết. Bên cạnh đó, nhiều nghiên cứu trước tìm thấy nhiều lợi ích mang lại cho các công ty khi minh bạch CSR cũng góp phần khẳng định tầm quan trọng của việc thực hiện và minh bạch CSR của các doanh nghiệp trong bối cảnh hội nhập kinh tế toàn cầu. Nhiều nghiên cứu trước đã cung cấp bằng chứng thống kê cho thấy khá nhiều các nhân tố có khả năng gây ảnh hưởng đến sự minh bạch CSR của các công ty. Tùy vào sụ khác biệt đặc thù của từng bối cảnh nghiên cứu sẽ có những nhân tố khác nhau ảnh hưởng đến sự minh bạch CSR, trong đó tập trung vào hai nhóm nhân tố chính gồm nhóm nhân tố đặc điểm công ty và nhóm nhân tố kiểm soát quản trị (KSQT).

Từ lâu, minh bạch CSR đã rất phổ biến tại các quốc gia có trình độ phát triển cao như Mỹ và Châu Âu, tuy nhiên vẫn còn khá xa lạ ở Việt Nam. Một trong số nguyên nhân khiến các công ty niêm yết Việt Nam vẫn còn khá thờ ơ với vấn đề minh bạch CSR là do vẫn còn thiếu vắng của các nghiên cứu thực nghiệm về minh bạch CSR cũng như các nhân tố nào có thể ảnh hưởng đến sự minh bạch CSR. Vì vậy chưa có đầy đủ cơ sở để đề xuất các hàm ý chính sách cũng như những giải pháp cụ thể nhằm cải thiện sự minh bạch CSR cho các công ty niêm yết ở Việt Nam. Từ đó cho thấy, nghiên cứu "Các nhân tố ảnh hưởng đến sự minh bạch CSR của các công ty niêm yết Việt Nam" là hoàn toàn cần thiết.

\section{Cơ sở lý thuyết}

\subsection{Khái niệm minh bạch trách nhiệm xã hội}

Có khá nhiều khái niệm minh bạch trách nhiệm xã hội (CSR) khác nhau được sử dụng tùy thuộc đặc điểm bối cảnh nghiên cứu. Theo Gray, Owen, và Maunders (1987), minh bạch CSR là quá trình truyền đạt các tác động về xã hội và môi trường của các tổ chức đến các nhóm lợi ích cụ thể trong xã hội nói chung. Theo Mathews (1997), minh bạch CSR là công bố các thông tin định tính và định lượng mang tính tự nguyện nhằm thông báo cho các bên liên quan được biết. Theo Van der Laan Smith, Adhikari, và Tondkar (2005), minh bạch CSR là công bố thông tin rộng rãi và đa dạng về sản phẩm, những tác động của công ty đến môi trường, trách nhiệm với người lao động, với nhà cung cấp, minh bạch về những đóng góp chính trị, hoạt động cộng đồng, đóng góp từ thiện và vấn đề an toàn sản phẩm đối với sức khỏe người tiêu dùng. 
Ngoài ra, GRI-Global Reporting Initiative (2006) là một bản hướng dẫn minh bạch CSR phổ biến trên thế giới đã định nghĩa minh bạch CSR là việc công bố các thông tin tự nguyện liên quan đến các nội dung (1) chiến lược và hồ sơ công ty; thông số báo cáo tài chính và quản trị công ty và (2) tiếp cận các góc độ quản lý bao gồm kinh tế, môi trường, lao động và việc làm, nhân quyền, cộng đồng và trách nhiệm đối với khách hàng và sản phẩm. Nghiên cứu này sử dụng cách khái nhiệm minh bạch CSR theo GRI.

\subsection{Các lý thuyết liên quan}

Có khá nhiều khung lý thuyết khác nhau giải thích cho sự minh bạch CSR được sử dụng trong nhiều nghiên cứu trước, bao gồm lý thuyết người đại diện (Akhtaruddin, Hossain, Hossain, \& Yao, 2009; Al-Janadi, Rahman, \& Omar, 2013), lý thuyết các bên liên quan ( Hossain, Perera, \& Rahman, 1995; Naser, Al-Hussaini, Al-Kwari, \& Nuseibeh, 2006; Roberts, 1992), lý thuyết hợp pháp (Islam \& Deegan, 2008), lý thuyết trách nhiệm (Gray et al., 1995), lý thuyết kinh tế chính trị (Amran \& Devi, 2008) và lý thuyết thể chế mới (Sobhani, Zainuddin, Amran, \& Baten, 2011). Tất cả luận điểm của các lý thuyết đều có ý nghĩa và tính thực tiễn riêng tùy vào tính đặc thù và bối cảnh của từng nghiên cứu. Trong đó, lý thuyết các bên liên quan và lý thuyết người đại diện được sử dụng phổ biến nhất trong việc giải thích sự minh bạch CSR. Hai lý thuyết này sẽ được sử dụng để giải thích kết quả của nghiên cứu.

\subsubsection{Lý thuyết các bên liên quan (Freeman, 1984)}

Lý thuyết này cho rằng công ty chỉ có thể tồn tại và phát triển bền vững chỉ khi đảm bảo đầy đủ quyền lợi cho tất cả các bên liên quan của công ty, chính là những cá nhân hoặc tổ chức có thể ảnh hưởng hoặc bị ảnh hưởng đáng kể từ công ty.

\subsubsection{Lý thuyết ngườ đại diện (Jensen \& Meckling, 1976)}

Lý thuyết này cho rằng luôn tồn tại xung đột lợi ích giữa các cổ đông và người quản lý vì không phải lúc nào lợi ích của họ cũng hòa hợp với nhau. Người đại diện quản lý sử dụng các nguồn lực chung của công ty nhằm phục vụ riêng bản thân họ hơn là phục vụ cho lợi ích chung của công ty. Lý thuyết này có thể đảm bảo giải quyết được 2 rắc rối phổ biến đó là (1) mục tiêu của người chủ và người đại diện quản lý không bị mâu thuẫn nhau và (2) người chủ và người đại diện quản lý cùng nhau thống nhất phương pháp giải quyết vấn đề cũng như đối phó với các rủi ro.

\subsection{Lự̛c khảo và xây dụng giả thuyết nghiên cứu}

Phần nội dung sau đây trình bày những giả thuyết được đề xuất trong nghiên cứu dựa trên cơ sở các tài liệu đã được lược khảo, đồng thời dựa trên đặc điểm và trình độ phát triển của TTCK Việt Nam.

\subsubsection{Mối quan hệ giữa các nhân tố đặc điểm công ty với sự minh bạch CSR}

Quy mô công ty: nghiên cứu sử dụng tổng tài sản đo lường cho quy mô công ty (Hossain et al., 1995). Để đảm bảo không làm chệch mô hình cũng như không làm thay đổi mối quan hệ giữa các biến, nghiên cứu lấy logarit tổng tài sản bởi tổng tài sản thường có giá trị rất lớn so với các biến khác trong mô hình (Meek, Roberts, \& Gray, 1995). Jensen và Meckling (1976) lập luận rằng các công ty lớn có nguy cơ gây thiệt hại cho môi trường nhiều hơn. Vì thế, các công ty này sẽ phải thực hiện và minh bạch CSR nhiều hơn, đặc biệt là về vấn đề môi trường. Hơn nữa, các công ty lớn sẽ có nguồn tài chính dồi dào và nhiều kinh nghiệm thực hiện và minh bạch CSR hơn. Hầu hết nhiều nghiên cứu trước tìm thấy sự ảnh hưởng cùng chiều của quy mô công ty đến sự minh bạch CSR (Giannarakis, 2014; Rosli, Fauzi, Azami, Mohd, \& Said, 2016). 


\section{H1: Quy mô công ty tác động tích cực đến mức độ minh bạch CSR}

Số năm hoạt động: lý thuyết hợp pháp (Suchman, 1995) lập luận rằng khi công ty hoạt động lâu năm trên thị trường sẽ có danh tiếng và uy tín cao hơn những công ty mới hoạt động vì các công ty hoạt động lâu năm thường sẽ có sự ổn định và phát triển bền vững hơn, có đủ nguồn lực, kinh nghiệm và ý thức trách nhiệm cao hơn trong việc xây dựng hình ảnh và danh tiếng bằng nhiều biện pháp trong đó có việc thực hiện và minh bạch CSR. Nhiều nghiên cứu đã tìm thấy sự ảnh hưởng cùng chiều giữa tuổi công ty và mức độ minh bạch CSR của công ty (Chakroun, Matoussi, \& Mbirki, 2017; Muttakin, Khan, \& Mihret, 2018).

H2: Có sự ảnh hưởng cùng chiều của tuổi của công ty đến mức độ minh bạch CSR

Đòn bẩy tài chính: chỉ số đòn bẩy tài chính đo lường mức độ sử dụng nợ vay của công ty trong việc mua sắm tài sản. Huafang và Jianguo (2007) lập luận rằng khi công ty vay nợ, các nhà cung cấp tín dụng sẽ giám sát công ty chặt chẽ hơn nhằm đảm bảo khả năng trả nợ và việc giám sát này gây tốn kém chi phí. Vì thế, các công ty sẽ chủ động minh bạch nhiều thông tin bao gồm thông tin CSR đến các bên liên quan, đặc biệt là chủ nợ nhằm nới lỏng sự giám sát để giảm chi phí. Giulio (2011) lập luận khi nợ vay càng nhiều thì mức độ minh bạch thông tin CSR càng cao. Một quan điểm khác cho rằng mức độ minh bạch CSR không chịu sự ảnh hưởng bởi nợ vay của công ty (Razak, 2015). Thậm chí, Maskun (2013) còn cho rằng nợ vay của công ty càng nhiều thì mức độ minh bạch thông tin bao gồm thông tin CSR sẽ giảm nhằm che giấu các điểm yếu của công ty và nhận định này cũng khá phù hợp với tâm lý của các doanh nghiệp tại Việt Nam.

\section{H3: Đòn bẩy tài chính của công ty ảnh hưởng ngược chiều đến mức độ minh bạch CSR}

Khả năng sinh lời: nghiên cứu sử dụng tỷ suất lợi nhuận sau thuế trên tổng tài sản (ROA) để đo lường khả năng sinh lời của công ty. Theo Akhtaruddin và cộng sự (2009), khi lợi nhuận kinh doanh càng cao, nhà quản trị càng thích minh bạch thông tin bao gồm thông tin CSR. Belkaoui và Karpik (1989) lập luận khi nhà quản trị có đủ kiến thức và năng lực tạo ra lợi nhuận thì chắc chắn họ cũng sẽ ý thức thực hiện và minh bạch CSR tốt hơn. Luethge và Han (2012) cũng lập luận khi có lợi nhuận tốt, các công ty sẽ có kinh phí thực hiện và minh bạch CSR nhiều hơn. Ngược lại, khi lợi nhuận kinh doanh giảm hoặc không có lợi nhuận, các công ty sẽ giảm mức độ minh bạch thông tin nhằm che giấu khiếm khuyết (García-Meca, Parra, Larrán, \& Martínez, 2005) và khi đó các công ty chỉ chú trọng thực hiện các biện pháp tăng thu nhập cho công ty, ít quan tâm đến các vấn đề khác của xã hội (Roberts, 1992). Những nhận định này cũng khá phù hợp với bối cảnh nghiên cứu cho các công ty niêm yết Việt Nam.

\section{H4: Khả năng sinh lời của công ty ảnh hương cùng chiều đến mức độ minh bạch CSR}

\subsubsection{Anh hưởng của các nhân tố kiểm soát quản trị đến sụ minh bạch CSR}

Quy mô Hội đồng quản trị: quy mô Hội đồng quản trị (HĐQT) thể hiện qua số lượng thành viên HĐQT. Theo lập luận của Akhtaruddin và cộng sự (2009), HĐQT là nhóm người thực hiện các quyết định, chính sách và chiến lược cho công ty, do đó số lượng và chất lượng HĐQT rất quan trọng. Nhiều nghiên cứu trước đã chỉ ra mối quan hệ ảnh hưởng giữa số lượng thành viên HĐQT và mức độ minh bạch CSR của công ty. Al-Janadi và cộng sự (2013) lập luận khi HĐQT có đông thành viên sẽ đủ nguồn lực thực hiện các chức năng quản trị, số lượng các quyết định quản trị tăng, do đó nhu cầu thông tin phục vụ cho việc ra quyết định cũng tăng theo, bao gồm thông tin bắt buộc lẫn tự nguyện CSR. Một nhận định khác của Giannarakis (2014) cho rằng nếu có quá đông thành viên HĐQT sẽ làm tăng nguy cơ xung đột lợi ích vì mỗi thành viên HĐQT đại diện cho mỗi nhóm cổ đông khác nhau, nên mức độ minh bạch CSR của công ty cũng sẽ giảm. Nghiên cứu cũng nghi ngờ rằng số lượng thành viên HĐQT và mức độ minh bạch CSR có mối quan hệ ngược chiều nhau. 


\section{H5: Quy mô HĐQT ảnh hương ngược chiều đến mức độ minh bạch CSR}

Sỵ kiêm chức của CEO: Lý thuyết người đại diện (Jensen \& Meckling, 1976) cho rằng việc $\mathrm{CEO}$ đồng thời là chủ tịch $\mathrm{HĐQT}$ sẽ làm giảm mức độ và hiệu quả giám sát độc lập của HĐQT đối với ban điều hành công ty. Chủ tịch HĐQT là người thiết lập nội dung các cuộc họp, là người bổ nhiệm và đánh giá năng lực của $\mathrm{CEO}$, vì vậy khi chủ tịch $\mathrm{HĐQT}$ kiêm chức $\mathrm{CEO}$ sẽ làm cho sự giám sát độc lập của HĐQT không còn khách quan (Ngo, Bui, \& Tran, 2017). Nhiều nghiên cứu trước đã chỉ ra mối quan hệ ngược chiều giữa sự kiêm chức $\mathrm{CEO}$ với mức độ minh bạch CSR của các công ty. Gul và Leung (2004); Samaha, Khlif, và Hussainey (2015) lập luận sự kiêm chức CEO khiến cho nhu cầu đáp ứng thông tin bao gồm thông tin CSR giảm xuống, từ đó khiến cho mức độ minh bạch CSR giảm dần. Nghiên cứu này cũng tin rằng tình trạng một người cùng một lúc giữ hai chức vụ $\mathrm{CEO}$ và chủ tịch $\mathrm{HĐQT} \mathrm{sẽ} \mathrm{có} \mathrm{những} \mathrm{tác} \mathrm{động} \mathrm{không} \mathrm{tích} \mathrm{cực} \mathrm{đến}$ sự minh bạch CSR của các công ty niêm yết Việt Nam.

\section{H6: Sụ kiêm chức của CEO sẽ làm giảm mức độ minh bạch CSR}

Tỷ lệ thành viên H円QT độc lập: theo Ngo và cộng sự (2017), thành viên HĐQT độc lập là những người không có quan hệ "lơi ích riêng tu" trong công ty, nên họ sẽ thường xuyên đưa ra nhều ý kiến khách quan nhất nhằm bảo vệ lợi ích chung của công ty. Mức độ độc lập của HĐQT được đo lường bằng tỷ lệ thành viên độc lập có trong HĐQT không tham gia giữ bất kỳ chức vụ nào trong ban điều hành công ty. Mức độ độc lập của HĐQT có các cấp độ từ thấp đến cao gồm (1) HĐQT có tất cả các thành viên đều tham gia vào ban điều hành; (2) HĐQT có phần lớn thành viên tham gia ban điều hành; (3) HĐQT có phần lớn thành viên không tham gia ban điều hành và (4) HĐQT không có bất kỳ thành viên nào tham gia ban điều hành. Lý thuyết người đại diện (Jensen $\&$ Meckling, 1976) cho rằng tỷ lệ này càng cao càng tốt vì sẽ làm tăng mức độ giám sát độc lập của HĐQT.

Khá nhiều nghiên cứu trước đã tìm thấy sự ảnh hưởng của mức độ độc lập của HĐQT đến sự minh bạch CSR. Ntim và Soobaroyen (2013) lập luận rằng khi tăng tỷ lệ thành viên HĐQT độc lập sẽ làm tăng mức độ minh bạch CSR của công ty. Nghiên cứu của Buniamin, Alrazi, Johari, và Rahman (2008) chỉ ra rằng giữa các báo cáo minh bạch CSR về môi trường và mức độ độc lập của HĐQT dường như không có bất kỳ mối quan hệ có ý nghĩa thống kê nào. Barako, Hancock, và Izan (2006) còn tìm thấy mối quan hệ ngược chiều giữa tỷ lệ thành viên HĐQT độc lập và mức độ minh bạch CSR của công ty. Điều này cho thấy vẫn còn nhiều kết luận trái chiều về mối quan hệ này giữa các nghiên cứu. Lý do có thể là do đặc điểm và trình độ phát triển của TTCK Việt Nam có một số khác biệt so với các quốc gia khác. Với đặc trưng là một thị trường mới nổi, trình độ cũng như chất lượng KSQT của các công ty Việt Nam vẫn còn thấp so với chuẩn quốc tế, tuy nhiên nghiên cứu vẫn kỳ vọng tỷ lệ thành viên HĐQT độc lập có sự ảnh hưởng tích cực đến mức độ minh bạch CSR của các công ty niêm yết ở Việt Nam.

\section{H7: Tỷ lệ thành viên HĐQT độc lập ảnh hương cùng chiều đến mức độ minh bạch CSR}

Ty lẹ sở hũu nhà nước: Tỷ lệ sở hữu nhà nước được đo lường bởi số cổ phần của nhà nước trên tổng số cổ phần của công ty. Với vai trò quản lý vĩ mồ, chính phủ sẽ làm việc theo chủ trương và định hướng chung về các mục tiêu kinh tế và chính trị của mỗi quốc gia cần đạt được. Tuy nhiên, với vai trò là cổ đông của một công ty, nhà nước lại phải quan tâm đến mục tiêu tối đa hóa lợi nhuận và tối đa giá trị của cổ đông. Xung đột có thể sẽ xảy ra khi chính phủ đảm nhận cùng lúc hai vai trò này (Ntim, Lindop, \& Thomas, 2013). Ntim và cộng sự (2013) cũng lập luận rằng khi tỷ lệ sở hữu nhà nước càng lớn sẽ thúc đẩy công ty minh bạch nhiều thông tin CSR hơn. Tuy nhiên, Al-Ajmi, Al-Mutairi, và Al-Duwaila (2015) lại cho rằng tỷ lệ sở hữu nhà nước cao sẽ khiến cho mức độ minh bạch thông tin trong đó có thông tin CSR của công ty sẽ kém đi. Điều này cho thấy vẫn còn nhiều kết luận khác nhau về tác động của tỷ lệ sở hữu nhà nước đến sự minh bạch CSR 
của công ty.

Theo Nguyen (2013), tại Việt Nam, các doanh nghiệp thuộc khu vực kinh tế nhà nước có hiệu quả kinh doanh kém hơn so với tất cả khu vực kinh tế khác. Đây cũng có thể là một cơ sở để nghiên cứu này nghi ngờ rằng việc có quá nhiều cổ phần sở hữu của nhà nước trong một công ty niêm yết có thể tác động không tốt đến mức độ minh bạch thông tin bao gồm thông tin CSR.

\section{H8: Tỷ lệ sở hữu nhà nước ảnh hưởng ngược chiều đến múc độ minh bạch CSR}

Tỷ lẹ sở hũu nước ngoài: Tỷ lệ sở hữu nước ngoài được đo lường bởi số cổ phần sở hữu của cổ đông nước ngoài trên tổng số cổ phần của công ty. Các nhà đầu tư nước ngoài nhất là các nước Châu Âu và Mỹ thường rất quan tâm đến vấn đề trách nhiệm đối với xã hội, người lao động và môi trường. Do vậy các công ty có sự hiện diện của cổ đông nước ngoài thường sẽ được yêu cầu minh bạch thông tin bao gồm thông tin CSR nhiều hơn (Soliman, Din, \& Sakr, 2013; Gunawan \& Lina, 2015). Ngoài ra, Cooke (1992) lập luận rằng do rào cản về không gian và ngôn ngũ̃, các cổ đông nước ngoài thường có nguy cơ phải đối mặt với tình trạng bất đối xứng thông tin cao hơn so với các loại cổ đông khác nên họ yêu cầu công ty phải minh bạch thông tin bao gồm thông tin CSR nhiều hơn. Jeon, Olivero, và Wu (2011) cho rằng khi vốn của cổ đông nước ngoài đầu tư vào một công ty đến một mức đủ cao thì các cổ đông này bắt đầu can thiệp vào công tác quản lý điều hành công ty, khi đó công ty sẽ chịu sự ảnh hưởng khá nhiều về phương thức quản lý và kinh doanh theo kiểu phương Tây, luôn chú trọng đến trách nhiệm đối với xã hội. Do đó, nghiên cứu này kỳ vọng với làn sóng đầu tư nước ngoài vào TTCK Việt Nam ngày càng mạnh mẽ sẽ tạo động lực thúc đẩy các công ty gia tăng sự minh bạch thông tin bao gồm thông tin CSR.

\section{H9: Tỷ lệ sở hũu nước ngoài ảnh hưởng tích cục đến mức độ minh bạch CSR}

Chất lượng kiểm toán: BIG4 là nhóm gồm 4 công ty kiểm toán quốc tế nổi tiếng (KPMG, Deloitte, Price Waterhouse Coopers, Ernst \& Young) đảm nhiệm vai trò tư vấn và kiểm toán cho nhiều tập đoàn lớn ở nước Anh. Các công ty trong nhóm này thường được hỗ trợ bởi nhiều chuyên gia nổi tiếng và danh tiếng là một trong những mối quan tâm hàng đầu của các công ty kiểm toán này. Các công ty thuộc nhóm BIG4 có khả năng khuyến khích khách hàng của họ cung cấp nhiều thông tin tài chính và thông tin CSR đa chiều hơn (Inchausti, 1997). Do đó, các công ty niêm yết sử dụng kiểm toán độc lập bởi các công ty thuộc nhóm BIG4 sẽ được xem là công ty có chất lượng kiểm toán tốt (Gupta \& Nayar, 2007). Barros, Boubaker, và Hamrouni (2013) đã lập luận những công ty có sử dụng kiểm toán thuộc nhóm BIG4, mức độ minh bạch thông tin CSR của công ty đó cao hơn. Tuy nhiên, một số nghiên cứu khác không tìm thấy sự ảnh hưởng có ý nghĩa thống kê giữa việc sử dụng dịch vụ kiểm toán thuộc nhóm BIG4 và mức độ minh bạch thông tin bao gồm thông tin CSR (Abd-Elsalam \& Weetman, 2003; Hossain et al., 1995). Các công ty kiểm toán thuộc nhóm BIG4 là nhóm công ty kiểm toán nước ngoài tồn tại ở Việt Nam lâu nhất nên có sự am hiểu nhất định về các công ty niêm yết ở Việt Nam. Do đó, nghiên cứu này cũng kỳ vọng có sự ảnh hưởng tích cực của việc sử dụng dịch vụ kiểm toán thuộc nhóm BIG4 đối với mức độ minh bạch CSR của các công ty niêm yết Việt Nam.

\section{H10: Việc sủ dụng kiểm toán thuộc BIG4 sẽ làm tăng mức độ minh bạch CSR}

\section{Phương pháp nghiên cứu}

\subsection{Cách tiếp cận số liệu minh bạch CSR}

Một số cách tiếp cận số liệu minh bạch CSR phổ biến được các tác giả sử dụng trong nhiều nghiên cứu bao gồm: (1) sử dụng các bộ dữ liệu thứ cấp xếp hạng chỉ số về danh tiếng và hiệu quả xã hội của các công ty do một số tổ chức uy tín theo dõi, đánh giá và liên tục trong nhiều năm (KLD, S\&P 500, Fortune,...); (2) thu thập dữ liệu sơ cấp bằng bảng hỏi điều tra phỏng vấn trực tiếp hoặc 
gián tiếp gửi email đến lãnh đạo công ty nhằm thu thập số liệu về minh bạch CSR và (3) phân tích nội dung các khoản mục thông tin CSR được trình bày trong các báo cáo thường niên của công ty. Ưu điểm của phương pháp phân tích nội dung (1) có tính linh hoạt rất cao, tùy thuộc vào mục đích nghiên cứu và đặc điểm thị trường nghiên cứu, tác giả có thể xây dựng thang đo thu thập thông tin minh bạch CSR phù hợp nhất cho nghiên cứu; (2) có khả năng tiếp cận số liệu minh bạch CSR khá dễ dàng với mức chi phí khá thấp. Vì vậy nghiên cứu sẽ sử dụng phương pháp phân tích nội dung để tiếp cận số liệu minh bạch CSR.

\subsection{Phuơng pháp thu thập số liệu}

Tổng thể nghiên cứu bao gồm tất cả các công ty cổ phần đại chúng đang niêm yết trên 2 sàn HOSE và HNX. Nghiên cứu sử dụng phương pháp chọn mẫu có chủ đích, những công ty đáp ứng được các đặc tính mong muốn với chủ đích của tác giả sẽ được đưa vào mẫu nghiên cứu. Cụ thể như sau: (1) Loại các công ty trong ngành tài chính ra khỏi mẫu nghiên cứu (vì các công ty trong ngành tài chính có quy định công bố thông tin riêng và có khác biệt so với các ngành còn lại); (2) Sau đó, loại các công ty đã thỏa mãn điều kiện 1 nhưng không có công bố báo cáo thường niên và báo cáo quản trị công ty liên tục đủ 5 năm từ 2013-2017. Cuối cùng, cỡ mẫu nghiên cứu còn lại chỉ bao gồm 323 công ty niêm yết phi tài chính (tương ứng với 1.615 quan sát) với tỷ lệ phân bổ mẫu như sau: 171 công ty ở sàn HOSE và 152 công ty ở sàn HNX. Các báo cáo được lấy từ www.hsx.vn, www.hnx.vn, www.cafef, www.Vietstock.vn, www.cophieu68.com và một số website chứng khoán khác.

Nghiên cứu thu thập số liệu thứ cấp bằng phương pháp phân tích nội dung, thu thập số liệu về minh bạch CSR được trình bày trong các báo cáo thường niên và báo cáo quản trị công ty. Phương pháp này có tính linh hoạt cao, giúp người nghiên cứu có thể thiết kế nội dung thang đo thu thập số liệu minh bạch CSR phù hợp theo mục đích của người nghiên cứu và đặc điểm thị trường nghiên cứu. Ngoài ra, khả năng tiếp cận số liệu minh bạch CSR của phương pháp này là khả thi với chi phí khá thấp. Chính vì vậy, phương pháp này được sử dụng phổ biến ở nhiều nghiên cứu về minh bạch CSR kể cả tại các thị trường phát triển và đang phát triển bao gồm Việt Nam (Suteja, Gunardi, \& Mirawati, 2016; Ta \& Bui, 2018).

Điểm số minh bạch CSR được đo lường từ 0-2 (nhận điểm 0 đối với các khoản mục cần thu thập thông tin CSR nhưng không có bất kỳ thông tin CSR nào được minh bạch; nhận điểm 1 khi có thông tin CSR được minh bạch ngắn gọn chung chung, không diễn giải và không có minh chứng và nhận điểm 2 khi có thông tin CSR được minh bạch chi tiết, được diễn giải thấu đáo và được minh họa bằng các minh chứng hình ảnh, số liệu biểu bảng...).

Nghiên cứu xây dựng thang đo minh bạch CSR dựa trên tham khảo từ (1) nội dung minh bạch CSR của bộ tiêu chí GRI và (2) thang đo minh bạch CSR của Bayoud, Kavanagh, và Slaughter (2012); Kansal, Joshi, và Batra (2014); Dias, Rodrigues, và Craig (2017). Thang đo minh bạch CSR tập vào nội dung thành phần và tương ứng với 30 các khoản chỉ mục đo lường chi tiết gồm: kinh tế ( 5 chỉ mục); môi trường (8 chỉ mục); người lao động ( 7 chỉ mục); cộng đồng (5 chỉ mục) và sản phẩm/khách hàng ( 5 chỉ mục).

Ngoài ra, nghiên cứu còn sử dụng thêm phương pháp tham vấn chuyên gia (bao gồm nhà nghiên cứu, chuyên gia quản lý nhà nước và lãnh đạo công ty) để đánh giá và hiệu chỉnh lại thang đo minh bạch CSR cho phù họp với thực tế của các công ty ở Việt Nam. Sau khi hiệu chỉnh, tác giả tiến hành thu thập thử số liệu minh bạch CSR của 5 công ty niêm yết có trong danh sách mẫu nghiên cứu để đánh giá lại mức độ phù hợp của thang đo và điều chỉnh lại thang đo (nếu có) để phù hợp nhất với đặc điểm minh bạch CSR của các công ty niêm yết tại Việt Nam. 


\subsection{Phưong pháp phân tích số liệu}

Do số liệu dạng bảng (panel data) và biến phụ thuộc là biến minh bạch CSR bị chặn nên nghiên cứu sử dụng đồng thời 2 mô hình ước lượng hồi quy Tobit theo dạng gộp (Pooled Tobit) và hồi quy Tobit có sự ảnh hưởng ngẫu nhiên (Random effects model Tobit-REM Tobit). Sau đó, dựa vào giá trị tuyệt đối Log likehood để lựa chọn mô hình ước lượng phù hợp cho việc trình bày và thảo luận kết quả nghiên cứu.

\section{Mô hình ước lượng của nghiên cứu có dạng như sau:}

$$
\operatorname{CSRD}_{\mathrm{i}, \mathrm{t}}=\beta_{0 \mathrm{i}, \mathrm{t}}+\beta_{\mathrm{j}} \mathrm{CC}_{\mathrm{i}, \mathrm{j}, \mathrm{t}}+\beta_{\mathrm{\gamma}} \mathrm{CG}_{\mathrm{i}, \mathrm{Y}, \mathrm{t}}+\mathrm{Z}_{\mathrm{i}, \mathrm{t}}+\varepsilon_{\mathrm{i}, \mathrm{t}}
$$

\section{Trong đó:}

$\mathrm{CSRD}_{\mathrm{i}, \mathrm{t}}$ được đo lường lần lượt là tổng điểm minh bạch CSR và điểm số minh bạch riêng của năm khía cạnh thành phần (kinh tế, môi trường, người lao động, cộng đồng và sản phẩm/khách hàng) của công ty $\mathrm{i}$ ở năm $\mathrm{t}$. Tổng điểm minh bạch CSR và điểm minh bạch của mỗi khía cạnh thành phần được lần lượt sử dụng như biến phụ thuộc. Do đó, mô hình nghiên cứu được ước lượng 6 lần với 6 biến phụ thuộc tương ứng.

$\mathrm{CC}_{\mathrm{i}, \mathrm{j}, \mathrm{t}}$ là biến đặc điểm thứ $\mathrm{j}$ của công ty $\mathrm{i}$ ở năm $\mathrm{t}(\mathrm{j}=1 \ldots, 4)$.

$\mathrm{CG}_{\mathrm{i}, \mathrm{Y}, \mathrm{t}}$ là biến KSQT thứ $\mathrm{Y}$ của công ty i ở năm $\mathrm{t}(\mathrm{V}=1 \ldots, 6)$.

$Z_{i, t}$ là biến kiểm soát ngành nghề của công ty $\mathrm{i}$ ở năm t. Theo Dye và Sridhar (1995), mỗi ngành có đặc điểm hoạt động, có số lượng và đặc điểm các bên liên quan cũng khác nhau. Ngoài ra, mỗi ngành sẽ có các quy định, chính sách và thông lệ minh bạch thông tin khác nhau nên có việc minh bạch CSR ở các ngành nghề có thể sẽ không giống nhau.

Các biến trong mô hình (1) được diễn giải chi tiết trong Bảng 1

\section{Bảng 1}

Diễn giải các biến trong mô hình (1)

\begin{tabular}{|c|c|c|c|c|c|}
\hline Tên biến & Ký hiệu & $\begin{array}{l}\text { Đơn vị } \\
\text { tính }\end{array}$ & Diễn giải & $\begin{array}{c}\text { Nguồn tham } \\
\text { khảo }\end{array}$ & $\begin{array}{c}\text { Dấu kỳ } \\
\text { vọng }\end{array}$ \\
\hline
\end{tabular}

\section{Biến phụ}

thuộc

Sự minh bạch

CSR chung

CSRD

Minh bạch kinh tế

ECO

Minh bạch môi trường

ENV Điểm

Minh bạch người lao động Đo lường tổng điểm minh bạch CSR chung bằng tổng điểm của năm khía sự (2012); Kansal Điểm cạnh minh bạch thành phần và cộng sự (2014); $(\mathrm{CSRD}=\mathrm{ECO}+\mathrm{ENV}+\mathrm{EMP}+\mathrm{COM}+\mathrm{PR} \quad$ Dias và cộng sự OCUS)

(2017)

Đo lường điểm minh bạch khía cạnh Điểm trách nhiệm kinh tế bằng tổng điểm của 5 mục đo lường cho khía cạnh kinh tế

Đo lường điểm minh bạch khía cạnh trách nhiệm môi trường bằng tổng điểm của 8 mục đo lường cho khía cạnh môi trường

Đo lường điểm minh bạch khía cạnh trách nhiệm người lao động bằng tổng điểm của 7 mục đo lường cho khía cạnh người lao động
Dias và cộng sự (2017)

Bayoud và cộng sự (2012); Kansal và cộng sự (2014)

Bayoud và cộng sự (2012); Kansal và cộng sự (2014) 


\begin{tabular}{|c|c|c|c|c|c|}
\hline Tên biến & Ký hiệu & $\begin{array}{l}\text { Đơn vị } \\
\text { tính }\end{array}$ & Diễn giải & $\begin{array}{l}\text { Nguồn tham } \\
\text { khảo }\end{array}$ & $\begin{array}{c}\text { Dấu kỳ } \\
\text { vọng }\end{array}$ \\
\hline $\begin{array}{l}\text { Minh bạch } \\
\text { cộng đồng }\end{array}$ & $\mathrm{COM}$ & Điểm & $\begin{array}{l}\text { Đo lường điểm minh bạch khía cạnh } \\
\text { trách nhiệm cộng đồng bằng tồng điềm } \\
\text { của } 5 \text { mục đo lường cho khía cạnh cộng } \\
\text { đồng }\end{array}$ & $\begin{array}{l}\text { Bayoud và cộng } \\
\text { sự (2012); Kansal } \\
\text { và cộng sự (2014) }\end{array}$ & \\
\hline $\begin{array}{l}\text { Minh bạch } \\
\text { SP/KH }\end{array}$ & PROCUS & Điểm & $\begin{array}{l}\text { Đo lường điểm minh bạch khía cạnh } \\
\text { trách nhiệm sản phẩm/khách hàng bằng } \\
\text { tổng điềm của } 5 \text { mục đo lường cho khía } \\
\text { cạnh } \mathrm{SP} / \mathrm{KH}\end{array}$ & $\begin{array}{l}\text { Bayoud và cộng } \\
\text { sự (2012); Kansal } \\
\text { và cộng sự (2014) }\end{array}$ & \\
\hline \multicolumn{6}{|l|}{ Biến độc lập } \\
\hline \multicolumn{6}{|l|}{$\begin{array}{l}\text { Biến đặc điểm } \\
\text { công ty }\end{array}$} \\
\hline $\begin{array}{l}\text { Quy mô công } \\
\text { ty }\end{array}$ & LNSIZE & & Logarit của tổng tài sản & $\begin{array}{l}\text { Rosli và cộng sự } \\
\text { (2016) }\end{array}$ & $(+)$ \\
\hline Tuổi công ty & YEAR & Năm & $\begin{array}{l}\text { Tính từ lúc bắt đầu thành lập đến thời } \\
\text { điểm hiện tại }\end{array}$ & $\begin{array}{l}\text { Chakroun và cộng } \\
\text { sự (2017) }\end{array}$ & $(+)$ \\
\hline $\begin{array}{l}\text { Khả năng sinh } \\
\text { lời }\end{array}$ & ROA & & Lợi nhuận sau thuế chia cho tổng tài sản & $\begin{array}{l}\text { Luethge và Han } \\
\text { (2012) }\end{array}$ & $(+)$ \\
\hline $\begin{array}{l}\text { Đòn bẩy tài } \\
\text { chính }\end{array}$ & LEV & & Tổng nợ chia cho tổng tài sản & Razak (2015) & $(-)$ \\
\hline \multicolumn{6}{|l|}{$\begin{array}{l}\text { Biến đặc điểm } \\
K S Q T\end{array}$} \\
\hline $\begin{array}{l}\text { Quy mô } \\
\text { HĐQT }\end{array}$ & BSIZE & $\begin{array}{l}\text { Số } \\
\text { thành } \\
\text { viên }\end{array}$ & Tổng số thành viên HĐQT & $\begin{array}{l}\text { Giannarakis } \\
\text { (2014) }\end{array}$ & $(-)$ \\
\hline $\begin{array}{l}\text { Tỷ lệ thành } \\
\text { viên độc lập } \\
\text { trong HĐQT }\end{array}$ & IND & $\%$ & $\begin{array}{l}\text { Số lượng thành viên HĐQT độc lập } \\
\text { trên tổng số thành viên HĐQT (Thành } \\
\text { viên HĐQT độc lập được định nghĩa là } \\
\text { thành viên HĐQT không giữ chức vụ } \\
\text { nào trong ban điều hành công ty) }\end{array}$ & $\begin{array}{l}\text { Ntim và } \\
\text { Soobaroyen } \\
\text { (2013) }\end{array}$ & $(+)$ \\
\hline $\begin{array}{l}\text { Sự kiêm chức } \\
\text { của } \mathrm{CEO}\end{array}$ & ВOTH & & $\begin{array}{l}\text { Nhận giá trị là } 1 \text { khi không có sự kiêm } \\
\text { chức, nhận giá trị là } 0 \text { khi có sự kiêm } \\
\text { chức }\end{array}$ & $\begin{array}{l}\text { Samaha và cộng } \\
\text { sự (2015) }\end{array}$ & $(-)$ \\
\hline $\begin{array}{l}\text { Chất lượng } \\
\text { kiểm toán }\end{array}$ & BIG4 & & $\begin{array}{l}\text { Nhận giá trị là } 1 \text { khi có sử dụng kiểm } \\
\text { toán thuộc BIG4, nhận giá trị là } 0 \text { khi } \\
\text { sử dụng kiểm toán không thuộc BIG4 }\end{array}$ & $\begin{array}{l}\text { Barros và cộng sự } \\
\text { (2013) }\end{array}$ & $(+)$ \\
\hline $\begin{array}{l}\text { Tỷ lệ sở hữu } \\
\text { nhà nước }\end{array}$ & SO & $\%$ & $\begin{array}{l}\text { Số lượng cổ phiếu do nhà nước sở hữu } \\
\text { trên tồng số cồ phiếu của công ty }\end{array}$ & $\begin{array}{l}\text { Al-Ajmi và cộng } \\
\text { sự (2015) }\end{array}$ & $(-)$ \\
\hline $\begin{array}{l}\text { Tỷ lệ sở hữu } \\
\text { nước ngoài }\end{array}$ & FO & $\%$ & $\begin{array}{l}\text { Số lượng cổ phiếu do cổ đông nước } \\
\text { ngoài trên tô̂ng số cổ phiếu của công ty }\end{array}$ & $\begin{array}{l}\text { Soliman và cộng } \\
\quad \text { sự (2013) }\end{array}$ & $(+)$ \\
\hline $\begin{array}{l}\text { Biến kiểm soát } \\
\text { ngành nghề }\end{array}$ & INDUSTRY & & $\begin{array}{l}\text { Mười biến giả ngành với biến ngành } \\
\text { xây dựng được sử dụng làm biến tham } \\
\text { chiếu }\end{array}$ & $\begin{array}{l}\text { Line, White, } \\
\text { Osmond, } \\
\text { Jennings, và } \\
\text { Mojonnier (2002) }\end{array}$ & \\
\hline
\end{tabular}

Trong đó: (+): cùng chiều; (-): ngược chiều

Nguồn: Tổng hợp từ các nghiên cứu lược khảo 


\section{Kết quả và thảo luận}

Trước khi đưa các biến vào phân tích hồi quy, từng cặp biến độc lập trong mô hình được kiểm định tương quan. Kết quả kiểm định cho thấy hệ số tương quan giữa các cặp biến độc lập nằm trong vùng giá trị cho phép (trị tuyệt đối của tất cả các hệ số tương quan đều $<0,5$ ).

Tổng điểm minh bạch CSR và điểm minh bạch của 5 khía cạnh thành phần được lần lượt phân tích bằng 2 mô hình Pooled Tobit và REM Tobit. Dựa vào giá trị tuyệt đối Log likelihood, mô hình ước lượng REM Tobit được chọn vì có giá trị tuyệt đối Log likelihood nhỏ hơn.

Kết quả phân tích REM Tobit ở bảng 3 cho thấy ở mức ý nghĩa $1 \%, 5 \%$ và $10 \%$, quy mô công ty có sự ảnh hưởng tích cực đáng kể đến tổng điểm minh bạch CSR chung và với tất cả năm khía cạnh minh bạch thành phần. Kết quả phân tích đã ủng hộ cho giả thuyết đặt ra và hoàn toàn tương đồng với nghiên cứu của Haniffa và Cooke (2005) và Rosli và cộng sự (2016).

Ngoài ra, tuổi của công ty có sự ảnh hưởng cùng chiều với tổng điểm minh bạch CSR chung, điểm minh bạch của khía cạnh môi trường và cộng đồng. Kết quả phân tích cho thấy thời gian hoạt động của công ty càng lâu năm thì công ty có mức độ minh bạch CSR càng nhiều. đặc biệt chú trọng minh bạch nhiều hơn ở khía cạnh môi trường và cộng đồng. Mặc dù vậy, kết quả phân tích lại cho thấy tuổi của công ty lại không có bất kỳ sự ảnh hưởng nào đến mức độ minh bạch của các khía cạnh thành phần còn lại. Nhìn chung, kết quả phân tích đã phần nào ủng hộ cho giả thuyết đặt ra và cũng thống nhất với các nghiên cứu của Muttakin và cộng sự (2018); Chakroun và cộng sự (2017).

Tỷ lệ sở hữu nước ngoài tác động tích cực đến tổng điểm minh bạch CSR và khía cạnh minh bạch môi trường. Kết quả phân tích cho thấy khi mức độ sở hữu của cổ đông nước ngoài trong công ty càng cao thì mức độ minh bạch CSR càng nhiều, đặc biệt chú trọng minh bạch tốt hơn ở khía cạnh trách nhiệm môi trường. Tuy nhiên, kết quả phân tích không tìm thấy bất kỳ sự liên quan nào giữa sở hữu nước ngoài và các khía cạnh minh bạch thành phần khác. Kết quả phân tích phần nào đã ủng hộ cho giả thuyết đặt ra và thống nhất với các nghiên cứu của Saleh, Zulkifli, và Muhamad (2010); Soliman và cộng sự (2013).

Tỷ lệ thành viên HĐQT độc lập tác động tích cực đến điểm minh bạch khía cạnh sản phẩm/khách hàng. Kết quả phân tích cho thấy khi tỷ lệ thành viên HĐQT độc lập càng lớn thì mức độ minh bạch trách nhiệm sản phẩm/ khách hàng càng cao. Tuy nhiên, tỷ lẹ̣ thành viên HĐQT độc lập trong các công ty niêm yết Việt Nam chưa có sự ảnh hưởng đáng kể đến các khía cạnh minh bạch thành phần khác. Kết quả phân tích chỉ phần nào ủng hộ cho giả thuyết đặt ra và có sự nhất quán với kết quả nghiên cứu của Said, Zainuddin, và Haron (2009); Ntim và cộng sự (2013).

Sự kiêm chức của $\mathrm{CEO}$ ảnh hưởng ngược chiều với tổng điểm minh bạch CSR và điểm minh bạch của tất cả năm khía cạnh trách nhiệm thành phần. Kết quả phân tích cho thấy khi công ty có hiện tượng CEO kiêm chức chủ tịch HĐQT thì mức độ minh bạch CSR sẽ thấp hơn các công ty không có hiện tượng kiêm chức của CEO. Kết quả phân tích ủng hộ cho giả thuyết đặt ra và hoàn toàn nhất quán với nghiên cứu của Gul và Leung (2004); Samaha và cộng sự (2015).

Tỷ lệ sở hữu nhà nước tác động ngược chiều đáng kể đến tổng điểm minh bạch CSR chung và điểm minh bạch của tất cả năm khía cạnh trách nhiệm thành phần. Kết quả phân tích cho thấy khi phần vốn sở hữu nhà nước trong công ty niêm yết Việt Nam càng cao thì mức độ minh bạch CSR càng thấp. Kết quả phân tích ủng hộ cho giả thuyết đặt ra và hoàn toàn thống nhất với nghiên cứu của Ismail và Ibrahim (2008) và Al-Ajmi và cộng sự (2015).

Bên cạnh đó, đòn bẩy tài chính có mối quan hệ ngược chiều đáng kể với tổng điểm minh bạch CSR chung và điểm của hầu hết các khía cạnh minh bạch thành phần (trừ khía cạnh sản 
phẩm/khách hàng). Kết quả này cho thấy tỷ lệ vay nợ của công ty càng nhiều sẽ càng làm giảm mức độ minh bạch CSR của công ty. Kết quả phân tích ủng hộ cho giả thuyết đặt ra và hoàn toàn thống nhất với nghiên cứu Maskun (2013) và Uyar, Kilic, và Bayyurt (2013).

\section{Bảng 2.}

Kết quả phân tích mối quan hệ giữa các nhân tố với mức độ minh bạch CSR của các công ty niêm yết Việt Nam giai đoạn 2013-2017

\begin{tabular}{|c|c|c|c|c|c|c|}
\hline Biến & Chung & Kinh tế & Môi trường & $\begin{array}{c}\text { Người lao } \\
\text { động }\end{array}$ & Cộng đồng & $\begin{array}{l}\text { Sản phẩm/ } \\
\text { Khách hàng }\end{array}$ \\
\hline Quy mô công ty & $\begin{array}{r}2,189 * * * \\
(0,252)\end{array}$ & $\begin{array}{r}0,165 * * * \\
(0,039)\end{array}$ & $\begin{array}{r}0,00 / 12) \\
\quad(0,12)\end{array}$ & $\begin{array}{r}0,703 * * * \\
(0,092)\end{array}$ & $\begin{array}{r}0,568 * * * \\
(0,082)\end{array}$ & $\begin{array}{r}0,144 * * * \\
(0,06)\end{array}$ \\
\hline Số năm hoạt động & $\begin{array}{l}\mathbf{0 , 0 7 4} * \\
(0,043)\end{array}$ & $\begin{array}{r}0,000 \\
(0,005)\end{array}$ & $\begin{array}{r}\mathbf{0 , 0 4 1} * * * \\
(0,016)\end{array}$ & $\begin{array}{r}0,009 \\
(0,014)\end{array}$ & $\begin{array}{r}\mathbf{0 , 0 2 *} \\
(0,013)\end{array}$ & $\begin{array}{r}0,004 \\
(0,014)\end{array}$ \\
\hline Đòn bẩy tài chính chính & $\begin{array}{r}-4,534 * * * \\
(1,277)\end{array}$ & $\begin{array}{r}-0,707 * * * * \\
(0,221)\end{array}$ & $\begin{array}{r}-1,391 * * * \\
(0,537)\end{array}$ & $\begin{array}{r}-1,968 * * * \\
(0,485)\end{array}$ & $\begin{array}{r}-0,713 * \\
(0,373)\end{array}$ & $\begin{array}{r}-0,241 \\
(0,281)\end{array}$ \\
\hline Lợi nhuận kinh doanh & $\begin{array}{l}2,549 * \\
(1,563)\end{array}$ & $\begin{array}{r}1,221 * * * \\
(0,281)\end{array}$ & $\begin{array}{r}0,286 \\
(0,628)\end{array}$ & $\begin{array}{r}0,174 \\
(0,607)\end{array}$ & $\begin{array}{r}0,215 \\
(0,524)\end{array}$ & $\begin{array}{l}\mathbf{0 , 6 1 7 *} \\
(0,386)\end{array}$ \\
\hline Quy mô HĐQT & $\begin{array}{r}-\mathbf{0 , 4 0 7 * * *} \\
(0,196)\end{array}$ & $\begin{array}{r}-0,01 \\
(0,035)\end{array}$ & $\begin{array}{r}-0,197 * * * \\
(0.081)\end{array}$ & $\begin{array}{r}-0,148 * * \\
(0,075)\end{array}$ & $\begin{array}{r}-0,118 * * \\
(0,556)\end{array}$ & $\begin{array}{r}-0,008 \\
(0,04)\end{array}$ \\
\hline Tỷ lệ TV HĐQT độc lập & $\begin{array}{r}0,009 \\
(0,011)\end{array}$ & $\begin{array}{r}0,002 \\
(0,002)\end{array}$ & $\begin{array}{r}-0,003 \\
(0,005)\end{array}$ & $\begin{array}{r}0,004 \\
(0,004)\end{array}$ & $\begin{array}{r}0,002 \\
(0,003)\end{array}$ & $\begin{array}{l}0,004 * \\
(0,002)\end{array}$ \\
\hline $\begin{array}{l}\text { CEO không kiêm chức } \\
\text { CT }\end{array}$ & $\begin{array}{r}1,497 * * * * \\
(0,482)\end{array}$ & $\begin{array}{r}0,196 * * \\
(0,089)\end{array}$ & $\begin{array}{r}0,309 * \\
(0,197)\end{array}$ & $\begin{array}{l}0,339 * \\
(0,184)\end{array}$ & $\begin{array}{r}0,345 * * * \\
(0,139)\end{array}$ & $\begin{array}{r}0,165^{*} \\
(0,1)\end{array}$ \\
\hline Có sử dụng BIG4 & $\begin{array}{l}-0,118 \\
(0,608)\end{array}$ & $\begin{array}{l}-0,052 \\
(0,116)\end{array}$ & $\begin{array}{r}0,112 \\
(0,247)\end{array}$ & $\begin{array}{l}-0,031 \\
(0,232)\end{array}$ & $\begin{array}{r}-0,189 \\
(0,165)\end{array}$ & $\begin{array}{l}-0,047 \\
(0,122)\end{array}$ \\
\hline Sở hữu nhà nước & $\begin{array}{r}-0,078 * * * * \\
(0,009)\end{array}$ & $\begin{array}{r}-0,008 * * * * \\
(0,002)\end{array}$ & $\begin{array}{r}-0,025 * * * \\
(0,004)\end{array}$ & $\begin{array}{r}-0,022 * * * \\
(0,003)\end{array}$ & $\begin{array}{r}-0,014 * * * \\
(0,003)\end{array}$ & $\begin{array}{r}-0,006 * * * * \\
(0,002)\end{array}$ \\
\hline Sở hữu nước ngoài & $\begin{array}{r}\mathbf{0 , 0 4 5} * * \\
(0,019)\end{array}$ & $\begin{array}{r}0,003 \\
(0,004) \\
\end{array}$ & $\begin{array}{r}\mathbf{0 , 0 1 9} * * * \\
(0,008)\end{array}$ & $\begin{array}{r}0,008 \\
(0,007) \\
\end{array}$ & $\begin{array}{r}0,003 \\
(0,005) \\
\end{array}$ & $\begin{array}{r}0,000 \\
(0,004) \\
\end{array}$ \\
\hline Log likelihood & $-5160,2327$ & $-2154,7465$ & $-3354,0705$ & $-3478,0188$ & $-2726,8904$ & $-2286,8722$ \\
\hline Giá trị $\mathrm{Chi}^{2}$ & 267,74 & 119,53 & 175,85 & 152,03 & 137,87 & 81,34 \\
\hline $\mathrm{p}$-value của giá trị $\mathrm{Chi}^{2}$ & 0,000 & 0,000 & 0,000 & 0,000 & 0,000 & 0,000 \\
\hline
\end{tabular}

Ghi chú: $(* * *),(* *)$ và (*) lần lượt có ý nghĩa thống kê ở mức $1 \%, 5 \%$ và $10 \%$.

Nguồn: kết quả phân tích số liệu từ 323 công ty niêm yết phi tài chính giai đoạn 2013-2017

Số lượng thành viên trong HĐQT tác động ngược chiều với tổng điểm minh bạch CSR chung và điểm số minh bạch của các khía cạnh môi trường, người lao động và cộng đồng. Kết quả phân tích cho thấy khi HĐQT của công ty càng đông thành viên thì mức độ minh bạch CSR càng giảm, đặc biệt giảm mức độ minh bạch ở các khía cạnh môi trường, người lao động và cộng đồng. Kết quả phân tích phần nào ủng hộ cho giả thuyết đặt ra và hoàn toàn tương đồng với nghiên cứu của Sufian và Zahan (2013) và Giannarakis (2014).

Việc sử dụng kiểm toán thuộc nhóm BIG4 không có bất kỳ sự liên quan nào đến mức độ 
minh bạch CSR của công ty. Kết quả phân tích cho thấy dù công ty có sử dụng kiểm toán độc lập thuộc nhóm BIG hay không cũng không ảnh hưởng đến mức độ minh bạch CSR. Kết quả phân tích này không ủng hộ giả thuyết đã đặt ra, tuy nhiên vẫn có sự tương đồng với các nghiên cứu của Hossain và cộng sự (1995); Abd-Elsalam và Weetman (2003).

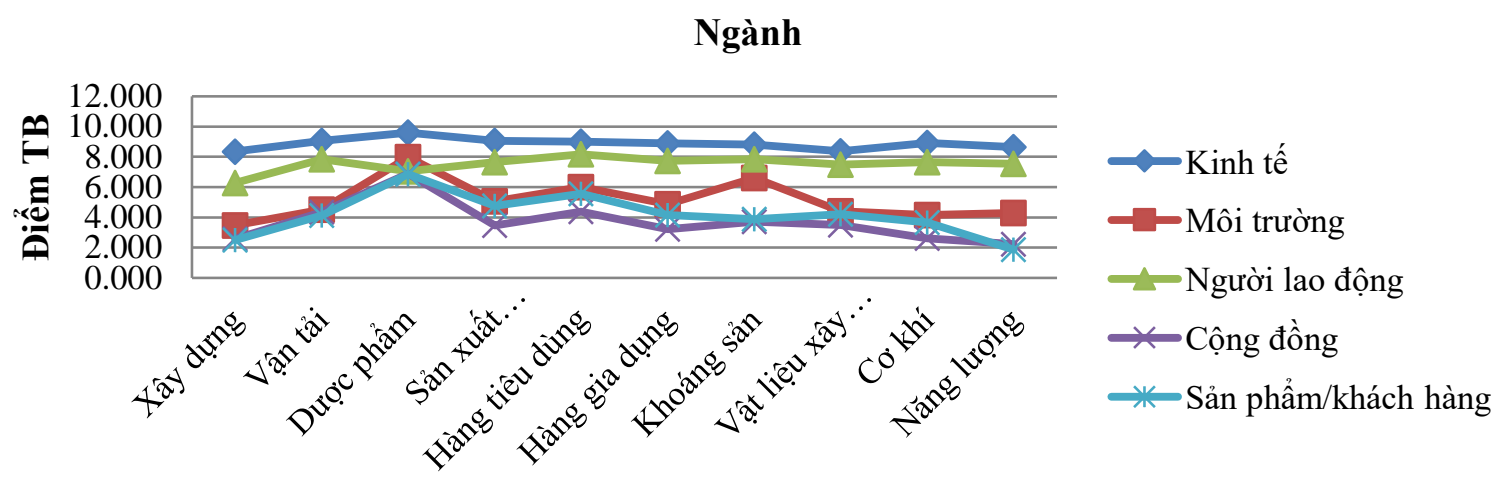

Hình 1. Điểm minh bạch trung bình 5 khía cạnh của các ngành giai đoạn 2013-2017

Kết quả hồi quy REM Tobit còn cho thấy có sự khác biệt giữa về hệ số ảnh hưởng của biến ngành nghề so với biến ngành tham chiếu (ngành xây dựng) ở tất cả các mô hình hồi quy. Điều này có nghĩa là các công ty niêm yết Việt Nam ở các ngành khác nhau sẽ thực hiện minh bạch CSR khác nhau. Kết quả này hoàn toàn thống nhất với các nghiên cứu của Waddock và Graves (1997); Line và cộng sự (2002). Bên cạnh đó, hình 1 còn cho biết sự minh bạch của các khía cạnh thành phần theo mỗi ngành nghề. Nhìn chung, cả năm khía cạnh minh bạch thành phần đều có mức độ khác nhau ở từng ngành nghề. Đáng chú ý là ngành sản xuất dược phẩm có nhiều khía cạnh minh bạch thành phần với điểm số cao nhất và cũng là ngành chú trọng minh bạch tốt nhất ở các khía cạnh môi trường, cộng đồng và sản phẩm/khách hàng. Bên cạnh đó, ngành sản xuất hàng tiêu dùng có mức độ minh bạch khía cạnh người lao động là cao nhất.

\section{Kết luận}

Bài viết nghiên cứu về các nhân tố ảnh hưởng đến mức độ minh bạch CSR của các công ty niêm yết trên thị trường chứng khoán Việt Nam. Dữ liệu được thu thập từ các báo cáo thường niên và báo cáo quản trị của 323 công ty niêm yết trên HOSE và HNX giai đoạn từ 2013-2017. Kết quả nghiên cứu cho thấy rằng quy mô càng lớn, lợi nhuận kinh doanh càng cao, cố năm hoạt động càng lâu, tỷ lệ thành viên HĐQT độc lập và tỷ lệ sở hữu nước ngoài càng cao thì mức độ minh bạch CSR của công ty càng cao. Ngoài ra, kết quả phân tích chỉ ra rằng tỷ lệ sử dụng nợ vay càng cao, số lượng thành viên HĐQT càng nhiều và tỷ lệ sở hữu nhà nước càng cao thì mức độ minh bạch $\mathrm{CSR}$ càng giảm. Bên cạnh đó, khi $\mathrm{CEO}$ vừa là chủ tịch HĐQT cũng sẽ khiến cho mức độ minh bạch CSR giảm xuống. Hiện tại, chưa có bằng chứng nào cho thấy việc lựa chọn công ty kiểm toán thuộc nhóm BIG4 có tác động đến mức độ minh bạch CSR của công ty. Thứ nhất có thể là do số lượng các công ty niêm yết Việt Nam hiện nay có sử dụng kiểm toán BIG4 còn rất ít, chỉ có một số ít các công ty lớn hoặc cần tiếp cận thị trường tài chính quốc tế thì mới sử dụng kiểm toán BIG4. Thứ hai, do trình độ KSQT của các công ty niêm yết Việt Nam hiện còn khá thấp, chưa đủ đáp ứng theo các tiêu chuẩn và thông lệ của kiểm toán quốc tế. Thứ ba, nhu cầu của các cổ đông về minh bạch báo cáo tài chính tại Việt Nam hiện nay cũng chưa cao. Thứ tư, một số công ty phải tuân thủ theo quy định báo cáo tài chính đặc thù ngành hoặc mỗi công ty sẽ có những nhu cầu khác nhau nên không lựa chọn kiểm toán thuộc nhóm BIG4. Cuối cùng có thể do mức phí dịch vụ kiểm toán BIG4 hiện còn quá cao cũng là nguyên nhân khiến các doanh nghiệp nhỏ và vừa không lựa chọn. Vì vậy cho đến thời điểm này vẫn chưa đủ cơ sở để kết luận rằng với mọi trường hợp công 
ty không sử dụng kiểm toán bằng BIG4 thì đều không thực hiện tốt việc minh bạch CSR.

Dựa trên kết quả nghiên cứu, một số hàm ý chính sách nhằm cải thiện sự minh bạch CSR của các công ty niêm yết Việt Nam được đề xuất cụ thể như sau: kết quả nghiên cứu chỉ ra rằng các công ty có tỷ lệ cổ phần nhà nước càng cao thì mức độ minh bạch thông tin bao gồm thông tin CSR càng ít. Do đó, đối với các công ty có vốn chi phối nhà nước đang cao và đang có kế hoạch cổ phần hóa thì nên đẩy nhanh tiến độ thoái bớt vốn nhà nước ra khỏi các công ty này, đặc biệt trong những ngành không cần thiết phải có vốn chi phối của nhà nước. Biện pháp này vừa cải thiện được mức độ minh bạch CSR, đồng thời cũng sẽ khắc phục được rủi ro do bất đối xứng thông tin đối với nhà đầu tư đặc biệt là nhà đầu tư nước ngoài, từ đó thu hút thêm nhiều nhà đầu tư đặc biệt nhà đầu tư nước ngoài nhằm gia tăng giá trị công ty trong tương lai. Ngoài ra, các công ty niêm yết Việt Nam nên điều chỉnh số lượng thành viên HĐQT ở mức tối thiểu nhất sao cho vừa đủ đáp ứng cho hoạt động quản trị công ty và vừa tránh được những bất đồng và xung đột giữa các thành viên trong HĐQT do mỗi thành viên HĐQT có thể đại diện cho mỗi nhóm cổ đông khác nhau. Đồng thời, thay vì chỉ quan tâm đến số lượng thành viên, các công ty nên quy định chi tiết thêm về cơ cấu thành phần HĐQT, quyền, nghĩa vụ, cách thức tổ chức và phối hợp giữa các thành viên trong HĐQT sao cho phù hợp và hiệu quả nhất. Ngoài ra, việc gia tăng mức độ giám sát độc lập của HĐQT sẽ làm tăng mức độ minh bạch CSR, do đó các công ty nên tăng tỷ lệ thành viên HĐQT độc lập, đồng thời nên tách rời hai chức vụ CEO và chủ tịch HĐQT ra nhằm tăng thêm tính khách quan trong hoạt động quản lý. Đồng thời, chính phủ cần ban hành thêm những quy định bắt buộc về việc này, tránh tình trạng một người nắm giữ cùng lúc cả hai chức vụ $\mathrm{CEO}$ và chủ tịch HĐQT nhằm nâng cao hiệu quả hoạt động KSQT cũng như gia tăng mức độ minh bạch CSR. Tuy chưa có bằng chứng cho thấy có sự tác động của việc sử dụng kiểm toán bằng BIG4 đến mức độ minh bạch CSR, nhưng để thích ứng với xu hướng hội nhập toàn cầu và tiếp cận nhanh với thị trường quốc tế thì trong thời gian tới các công ty niêm yết Việt Nam cũng nên xem xét việc sử dụng dịch vụ kiểm toán thuộc nhóm BIG4 cho công ty của mình nhằm đáp ứng với chuẩn quy định và thông lệ quốc tế.

\section{Tài liệu tham khảo}

Abd-Elsalam, O. H., \& Weetman, P. (2003). Introducing international accounting standards to an emerging capital market: Relative familiarity and language effect in Egypt. Journal of International Accounting, Auditing and Taxation, 12(1), 63-84.

Academy of Managers for Construction and Cities. (2018). Tầm nhìn đô thị thông minh tại Việt Nam [Smart urban's vision in Vietnam]. Retrieved March 25, 2020, from http://amc.edu.vn/vi/tin-tuc-su-kien/tin-xay-dung-va-do-thi/khoa-hoc-cong-nghe-moitruong/7136-tam-nhin-do-thi-thong-minh-tai-viet-nam.html

Akhtaruddin, M., Hossain, M. A., Hossain, M., \& Yao, L. (2009). Corporate governance and voluntary disclosure in corporate annual reports of Malaysian listed firms. Journal of Applied Management Accounting Research, 7(1), 1-19.

Al-Ajmi, M., Al-Mutairi, A., \& Al-Duwaila, N. (2015). Corporate social disclosure practices in Kuwait. International Journal of Economics and Finance, 7(9), 244-254. doi:10.5539/ijef.v7n9p244

Al-Janadi, Y., Rahman, R. A., \& Omar, N. B. (2013). Corporate governance mechanisms and voluntary disclosure in Saudi Arabia. Research Journal of Finance and Accounting, 4(4), 25-35. doi:10.1057/jdg.2011.19 
Allouche, J., \& Laroche, P. (2006). The relationship between corporate social responsibility and corporate financial performance: A survey. Corporate Social Responsibility: Performance and Stakeholders, 2, 3-40.

Amran, A., \& Devi, S. S. (2008). The impact of government and foreign affiliate influence on corporate social reporting: The case of Malaysia. Managerial Auditing Journal, 23(4), 386-404.

Barako, D. G., Hancock, P., \& Izan, H. Y. (2006). Factors influencing voluntary corporate disclosure by Kenyan companies. Corporate Governance: An International Review, 14(2), 107-125.

Barros, C. P., Boubaker, S., \& Hamrouni, A. (2013). Corporate governance and voluntary disclosure in France. Journal of Applied Business Research (JABR), 29(2), 561-578.

Bayoud, N. S., Kavanagh, M., \& Slaughter, G. (2012). Factors influencing levels of corporate social responsibility disclosure Libyan firms: A mixed study. International Journal of Economics and Finance, 4(4), 13-29.

Belkaoui, A., \& Karpik, P. G. (1989). Determinants of the corporate decision to disclose social information. Accounting, Auditing \& Accountability Journal, 2(1).

Brown, T. J., \& Dacin, P. A. (1997). The company and the product: Corporate associations and consumer product responses. The Journal of Marketing, 61(1), 68-84.

Buniamin, S., Alrazi, B., Johari, N. H., \& Rahman, N. R. A. (2008). An investigation of the association between corporate governance and environmental reporting in Malaysia. Asian Journal of Business and Accounting, 1(2), 65-99.

Chakroun, R., Matoussi, H., \& Mbirki, S. (2017). Determinants of CSR disclosure of Tunisian listed banks: A multi-support analysis. Social Responsibility Journal, 13(3), 552-584.

Chou, L, C., Chang, T. C., Darcy, J., \& Yan, Y. (2017). The impact of social responsibility on corporate performance: Evidence from Taiwan. Accounting and Finance Research, 6(2), 181-189. doi:10.5430/afr.v6n2p181

Cooke, T. E. (1992). The impact of size, stock market listing and industry type on disclosure in the annual reports of Japanese listed corporations. Accounting and Business Research, 22(87), 229-237.

Dias, A., Rodrigues, L. L., \& Craig, R. (2017). Corporate governance effects on social responsibility disclosures. Australasian Accounting, Business and Finance Journal, 11(2), 3-22.

Dye, R. A., \& Sridhar, S. S. (1995). Industry-wide disclosure dynamics. Journal of Accounting Research, 33(1), 157-174.

Eng, L. L., \& Mak, Y. T. (2003). Corporate governance and voluntary disclosure. Journal of Accounting and Public Policy, 22(4), 325-345. doi:10.1016/S0278-4254(03)00037-1

Erhemjamts, O., Li, Q., \& Venkateswaran, A. (2013). Corporate social responsibility and its impact on firms' investment policy, organizational structure, and performance. Journal of Business Ethics, 118(2), 395-412. doi:10.1007/s10551-012-1594-X

Freeman, R. (1984). Strategic management: A stakeholder approach. Boston, MA: Pitman.

García-Meca, E., Parra, I., Larrán, M., \& Martínez, I. (2005). The explanatory factors of intellectual capital disclosure to financial analysts. European Accounting Review, 14(1), 63-94. 
Giannarakis, G. (2014). The determinants influencing the extent of CSR disclosure. International Journal of Law and Management, 56(5), 393-416. doi:10.1108/IJLMA-05-2013-0021

Giulio, M. D. (2011). Principali, principianti. Le regioni e il trasporto ferroviario locale (19972011). Rivista Italiana Di Politiche Pubbliche, 6(3), 530-533.

Global Reporting Initiative. (2006). Sustainability Reporting Guidelines v3.0. Amsterdam: GRI.

Gray, R., Kouhy, R., Lavers, S., Gray, R., Kouhy, R., \& Lavers, S. (1995). Longitudinal study of UK disclosure. Accounting, Auditing \& Accountability Journal, 2, 47-77.

Gray, R., Owen, D., \& Maunders, K. (1987). Corporate social reporting: Accounting and accountability. Upper Saddle River, NJ: Prentice-Hall International.

Gul, F. A., \& Leung, S. (2004). Board leadership, outside directors' expertise and voluntary corporate disclosures. Journal of Accounting and Public Policy, 23(5), 351-379.

Gunawan, S., \& Lina, L. (2015). Factors influencing corporate social responsibility disclosure: Evidence in Indonesia. Universitas Pelita Harapan Institutional Repository, 881-891.

Gupta, P. P., \& Nayar, N. (2007). Information content of control deficiency disclosures under the Sarbanes-Oxley Act: An empirical investigation. International Journal of Disclosure and Governance, 4(1), 3-23.

Haniffa, R. M., \& Cooke, T. E. (2005). The impact of culture and governance on corporate social reporting. Journal of Accounting and Public Policy, 24(5), 391-430.

Hossain, M., Perera, M. H. B., \& Rahman, A. R. (1995). Voluntary disclosure in the annual reports of New Zealand companies. Journal of International Financial Management \& Accounting, 6(1), 69-87.

Huafang, X., \& Jianguo, Y. (2007). Ownership structure, board composition and corporate voluntary disclosure. Managerial Auditing Journal, 22(6), 604-619. doi:10.1108/02686900710759406

Inchausti, B. G. (1997). The influence of company characteristics and accounting regulation on information disclosed by Spanish firms. European Accounting Review, 6(1), 45-68.

Islam, M. A., \& Deegan, C. (2008). Motivations for an organisation within a developing country to report social responsibility information: Evidence from Bangladesh. Accounting, Auditing \& Accountability Journal, 21(6), 850-874.

Ismail, K. N. I. K., \& Ibrahim, A. (2008). Social and environmental disclosure in the annual reports of Jordanian companies. Social and Environmental Accounting, 2(2), 198-210. doi:10.22164/isea.v2i2.32

Jensen, M. C., \& Meckling, W. H. (1976). Theory of the firm: Managerial behavior, agency costs and ownership structure. Journal of Financial Economics, 3(4), 305-360.

Jeon, B. N., Olivero, M. P., \& Wu, J. (2011). Do foreign banks increase competition? Evidence from emerging Asian and Latin American banking markets. Journal of Banking \& Finance, 35(4), 856-875.

Kansal, M., Joshi, M., \& Batra, G. S. (2014). Determinants of corporate social responsibility disclosures: Evidence from India. Advances in Accounting, 30(1), 217-229. doi:10.1016/j.adiac.2014.03.009

Laufer, W. S. (2003). Social accountability and corporate greenwashing. Journal of Business Ethics, 43(3), 253-261. doi:10.1023/A:1022962719299 
Line, D. E., White, N. M., Osmond, D. L., Jennings, G. D., \& Mojonnier, C. B. (2002). Pollutant export from various land uses in the Upper Neuse River Basin. Water Environment Research, 74(1), 100-108.

Luethge, D., \& Han, H. G. (2012). Assessing corporate social and financial performance in China. Social Responsibility Journal, 8(3), 389-403.

Maskun, A. (2013). Leverage level, company size, profitability toward the disclosure of Corporate Social Responsibility (CSR) of LQ-45 companies in indonesia stock exchange. International Journal of Academic Research, 5(2), 140-144.

Mathews, M. R. (1997). Twenty-five years of social and environmental accounting research: Is there a silver jubilee to celebrate? Accounting, Auditing \& Accountability Journal, 10(4), 481-531. doi:10.1108/EUM0000000004417

Meek, G. K., Roberts, C. B., \& Gray, S. J. (1995). Factors influencing voluntary annual report disclosures by US, UK and continental European multinational corporations. Journal of International Business Studies, 26(3), 555-572.

Moon, J., \& Vogel, D. (2009). Corporate social responsibility, government, and civil society. In A. Crane, D. Matten, A. McWilliams, J. Moon \& D. S. Siegel (Eds.), The Oxford handbook of corporate social responsibility. Oxford, UK: Oxford University Press.

Muttakin, M. B., Khan, A., \& Mihret, D. G. (2018). The effect of board capital and CEO power on corporate social responsibility disclosures. Journal of Business Ethics, 150(1), 41-56.

Naser, K., Al-Hussaini, A., Al-Kwari, D., \& Nuseibeh, R. (2006). Determinants of corporate social disclosure in developing countries: The case of Qatar. Advances in International Accounting, 19, 1-23. doi:10.1016/S0897-3660(06)19001-7

Ng, E. J., \& Koh, H. C. (1994). An agency theory and probit analytic approach to corporate nonmandatory disclosure compliance. Asia-Pacific Journal of Accounting, 1(1), 29-44.

Ngo, T. M., Bui, V. T., \& Tran, N. T. N. (2017). Kiểm soát quản trị và sự tự nguyện công bố thông tin của các công ty niêm yết trên Sàn giao dịch chứng khoán TP. Hồ Chí Minh [Controlling the governance and voluntary information disclosure of companies listed on the Ho Chi Minh Stock Exchange]. Phát Triển và Hội Nhập, 37, 73-82.

Nguyen, C. T. (2013). Nhìn lại hiệu quả hoạt động của doanh nghiệp nhà nước so với các loại doanh nghiệp khác [Looking back at the performance of state-owned enterprises compared to other types of businesses]. Phát triển Kinh tế, 268, 1-11.

Ntim, C. G., \& Soobaroyen, T. (2013). Corporate governance and performance in socially responsible corporations: New empirical insights from a Neo-Institutional framework. Corporate Governance: An International Review, 21(5), 468-494.

Ntim, C. G., Lindop, S., \& Thomas, D. A. (2013). Corporate governance and risk reporting in South Africa: A study of corporate risk disclosures in the pre-and post-2007/2008 global financial crisis periods. International Review of Financial Analysis, 30, 363-383.

Razak, R. A. (2015). Corporate social responsibility disclosure and its determinants in Saudi Arabia. Middle-East Journal of Scientific Research, 23(10), 2388-2398. doi:10.5829/idosi.mejsr.2015.23.10.22768

Rettab, B., Brik, A. B., \& Mellahi, K. (2009). A study of management perceptions of the impact of corporate social responsibility on organisational performance in emerging economies: The case of Dubai. Journal of Business Ethics, 89(3), 371-390.

Roberts, R. W. (1992). Determinants of corporate social responsibility disclosure: An application of stakeholder theory. Accounting, Organizations and Society, 17(6), 595-612. 
Rosli, M. H., Fauzi, N. A., Azami, M. F. A. M., Mohd, F., \& Said, J. (2016). Company characteristics and corporate social responsibility disclosure of Malaysian listed companies. International Conference on Accounting Studies (ICAS) 2016, 15-18 August 2016, Langkawi, Kedah, Malaysia, 68-75.

Rustiarini, N. W. (2011). Pengaruh struktur kepemilikan saham pada pengungkapan corporate social responsibility. Jurnal Ilmiah Akuntansi Dan Bisnis, 6(1).

Said, R., Zainuddin, H. Y., \& Haron, H. (2009). The relationship between corporate social responsibility disclosure and corporate governance characteristics in Malaysian public listed companies. Social Responsibility Journal, 5(2), 212-226. doi:10.1108/17471110910964496

Saleh, M., Zulkifli, N., \& Muhamad, R. (2010). Corporate social responsibility disclosure and its relation on institutional ownership: Evidence from public listed companies in Malaysia. Managerial Auditing Journal, 25(6), 591-613.

Samaha, K., Khlif, H., \& Hussainey, K. (2015). The impact of board and audit committee characteristics on voluntary disclosure: A meta-analysis. Journal of International Accounting, Auditing and Taxation, 24, 13-28.

Sobhani, F. A., Zainuddin, Y., Amran, A., \& Baten, M. A. (2011). Corporate sustainability disclosure practices of selected banks: A trend analysis approach. African Journal of Business Management, 5(7), 2794-2804.

Soliman, M., Din, M. E., \& Sakr, A. (2013). Ownership structure and Corporate Social Responsibility (CSR): An empirical study of the listed companies in Egypt. SSRN Electronic Journal, 5(1), 63-74.

Suchman, M. C. (1995). Managing legitimacy: Strategic and institutional approaches. Academy of Management Review, 20(3), 571-610.

Sufian, M. A., \& Zahan, M. (2013). Ownership structure and corporate social responsibility disclosure in Bangladesh. International Journal of Economics and Financial Issues, 3(4), 901-909.

Suteja, J., Gunardi, A., \& Mirawati, A. (2016). Moderating effect of earnings management on the relationship between corporate social responsibility disclosure and profitability of banks in Indonesia. International Journal of Economics and Financial Issues, 6(4), 1360-1365.

Ta, H. T. T., \& Bui, N. T. (2018). Effect of Corporate Social Responsibility Disclosure on Financial Performance. Asian Journal of Finance \& Accounting, 10(1), 40-58. doi:10.5296/ajfa.v10i1.12592

Uyar, A., Kilic, M., \& Bayyurt, N. (2013). Association between firm characteristics and corporate voluntary disclosure: Evidence from Turkish listed companies. Intangible Capital, 9(4), 1080-1112.

Van der Laan Smith, J., Adhikari, A., \& Tondkar, R. H. (2005). Exploring differences in social disclosures internationally: A stakeholder perspective. Journal of Accounting and Public Policy, 24(2), 123-151.

Waddock, S. A., \& Graves, S. B. (1997). The corporate social performance-financial performance link. Strategic Management Journal, 18(4), 303-319. 